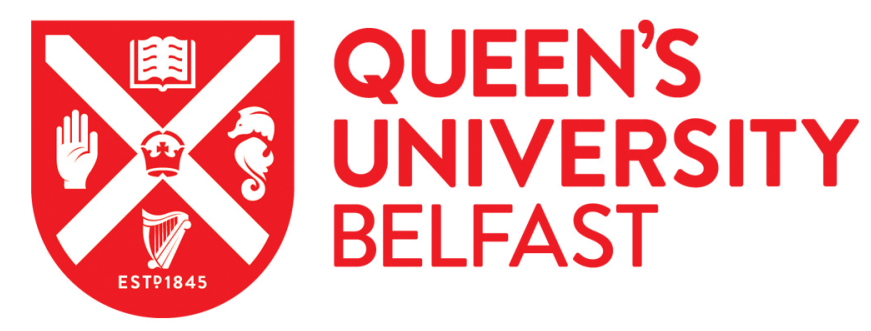

\title{
Cell salvage alters the systemic inflammatory response after off-pump coronary artery bypass grafting surgery
}

\author{
Allen, S. J., McBride, W. T., McMurray, T. J., Phillips, A. S., Penugonda, S. P., Campalani, G., Young, I., \& \\ Armstrong, M. (2007). Cell salvage alters the systemic inflammatory response after off-pump coronary artery \\ bypass grafting surgery. The Annals of Thoracic Surgery, 83(2), 578-585. \\ https://doi.org/10.1016/j.athoracsur.2006.09.041
}

Published in:

The Annals of Thoracic Surgery

Queen's University Belfast - Research Portal:

Link to publication record in Queen's University Belfast Research Portal

\section{General rights}

Copyright for the publications made accessible via the Queen's University Belfast Research Portal is retained by the author(s) and / or other copyright owners and it is a condition of accessing these publications that users recognise and abide by the legal requirements associated with these rights.

Take down policy

The Research Portal is Queen's institutional repository that provides access to Queen's research output. Every effort has been made to ensure that content in the Research Portal does not infringe any person's rights, or applicable UK laws. If you discover content in the Research Portal that you believe breaches copyright or violates any law, please contact openaccess@qub.ac.uk. 


\title{
Cell Salvage Alters the Systemic Inflammatory Response After Off-Pump Coronary Artery Bypass Grafting Surgery
}

\author{
Stephen J. Allen, MD, William T. McBride, MD, Terence J. McMurray, MD, \\ Anne S. Phillips, MD, S. Prasad Penugonda, MB BCh, Gianfranco Campalani, MD, \\ Ian S. Young, PhD, and Marilyn A. Armstrong, PhD
}

Departments of Clinical Anaesthesia and Cardiothoracic Surgery, Royal Group of Hospitals Trust; Departments of Anaesthetics and Intensive Care, Immunobiology, and Clinical Chemistry, Queens University, Belfast, Ireland

Background. Retransfused cardiotomy suction blood contains elevated inflammatory markers and is a bypass independent source of inflammatory mediators. We hypothesized that, during off-pump coronary artery bypass (OPCAB) grafting surgery, avoiding retransfusion of unwashed cardiotomy suction blood would beneficially alter both urinary and plasma cytokine concentrations and be renoprotective.

Methods. Thirty-seven ОРСАВ surgery patients were randomly allocated to control (retransfusion of unwashed shed blood) and treatment (retransfusion of washed shed blood or discarding of unwashed blood) groups. Over 72 hours we measured plasma (tumor necrosis factor- $\alpha$ [TNF- $\alpha$ ], interleukin-8, interleukin-6, interleukin-10, TNF soluble receptor-2, and interleukin-1 receptor antagonist) and urinary TNF soluble receptor-2 and interleukin-1 receptor antagonist and markers of renal injury and dysfunction ( $\mathrm{N}$-acetyl $\beta \mathrm{D}$ glucosaminidase and $\alpha_{1}$-microglobulin).

$\mathrm{T}$ he perioperative inflammatory response arises from cardiopulmonary bypass dependent $[1,2]$, as well as bypass independent, processes [3-5]. Traditionally, the magnitude of this response is determined in the laboratory by assessing humoral and cellular markers of inflammatory activity in the blood [6, 7]. Such humoral indicators of inflammation include increased plasma proinflammatory cytokines usually accompanied by a compensatory increase in plasma anti-inflammatory cytokines $[3,4,8-10]$.

Recently, urinary anti-inflammatory cytokines have been found to increase at cardiac surgery even before detectable increases in plasma proinflammatory mediators $[3,10]$. These urinary anti-inflammatory cytokines are thought to constitute an early, intrarenal, protective mechanism for controlling intrarenal proinflammatory activity arising from either filtered plasma proinflammatory or intrarenally generated cytokines [11]. Thus, the

Accepted for publication Sept 11, 2006.

Address correspondence to Dr Allen, Department of Clinical Anaesthesia, Royal Group of Hospitals Trust, Grosvenor Rd, Belfast, N. Ireland, United Kingdom BT12 6BA; e-mail: stephen.allen@royalhospitals.n-i.nhs.uk.
Results. We demonstrated elevated proinflammatory cytokines in cardiotomy suction blood, which were effectively eliminated by cell salvage. After retransfusion, in comparison with controls, the treatment group had reduced plasma TNF soluble receptor-2. As compared with controls, treatment group patients also demonstrated significantly reduced levels of the urinary antiinflammatory cytokine TNF soluble receptor-2. There were no between group differences in markers of renal injury or dysfunction.

Conclusions. We have demonstrated that the management of shed mediastinal blood alters perioperative, systemic, plasma and urinary cytokine homeostasis at OPCAB surgery but does not impact on subclinical renal injury or dysfunction in this low risk group of patients.

(Ann Thorac Surg 2007;83:578-85)

(C) 2007 by The Society of Thoracic Surgeons

urinary anti-inflammatory cytokine response provides a useful early means of quantifying the magnitude of an evolving upstream plasma proinflammatory response.

Of greater clinical relevance than the above is the determination of the pathophysiological effect of this response. Thus, for example, perioperative subclinical renal injury at cardiac surgery is thought to arise, at least in part, from the effects of the perioperative inflammatory response. Subclinical renal injury can be estimated through determining urinary $\mathrm{N}$-acetyl $\beta \mathrm{D}$ glucosaminidase ( $\beta$-NAG)/creatinine ratios [12-14]. Subclinical renal dysfunction can be measured by the failure of the proximal tubule to reabsorb $\alpha_{1}$-microglobulin [14, 15].

A logical approach to minimizing the perioperative inflammatory response would be to avoid exposure of the patient to cardiopulmonary bypass. We [3], and others [16-21], have shown that performing cardiac surgery "off-pump" (off-pump coronary artery bypass [OPCAB] surgery) may result in a reduction, but not elimination, of the inflammatory response.

Similarly, OPCAB surgery has variable but limited effects on renal function after cardiopulmonary bypass. 
There are theoretical reasons why such surgery should be renoprotective, including better preservation of hemodynamic parameters, increased fluid loading, reduced inflammatory response, and a reduction in filtered nephrotoxins such as free hemoglobin and proinflammatory cytokines. However, these theoretical benefits have not substantially reduced renal injury or dysfunction [3, 22-26].

The failure of OPCAB surgery to eliminate the inflammatory response and subsequent renal injury highlights the multifactorial etiology of the inflammatory response after cardiopulmonary bypass. One factor contributing to this inflammatory response is retransfusion of shed mediastinal blood after cardiopulmonary bypass. Shed mediastinal blood contains elevated levels of inflammatory markers [27-29]. This has also been shown in shed blood after orthopedic surgery, where the retransfusion of this blood resulted in proinflammatory alterations in the patient's systemic cytokine profile [30-32]. Several groups have demonstrated that the use of cell savers reduces the level of inflammatory mediators in shed mediastinal blood $[29,33]$. Westerberg and colleagues [34] recently reported reduced plasma interleukin- 6 and $\mathrm{C} 3 \mathrm{a}$ after cardiopulmonary bypass in patients whose cardiotomy suction blood had been discarded. However, the important contribution of plasma and urinary anti-inflammatory cytokines was not explored nor did they investigate the possibility of washing shed blood prior to retransfusion. Furthermore, the possible anti-inflammatory benefits of discarding shed mediastinal blood are likely to be offset by disadvantageous blood wastage, particularly if cardiotomy bleeding is excessive. It is therefore important to establish whether transfusion of washed mediastinal shed blood has anti-inflammatory benefits without compromising blood conservation. In this paper we examine the hypothesis that avoiding the retransfusion of unwashed shed mediastinal blood, in comparison with administration of unwashed blood, would beneficially alter plasma and urinary cytokine homeostasis and result in reduced subclinical renal injury or dysfunction after OPCAB surgery.

\section{Patients and Methods}

Thirty-seven patients undergoing elective coronary artery revascularization surgery without cardiopulmonary bypass were studied after written, informed consent had been obtained. Local ethical committee approval was obtained prior to study commencement. Exclusion criteria were unstable angina, myocardial infarction within the previous three months, diabetes mellitus, elevated serum creatinine greater than $120 \mu \mathrm{mol} \mathrm{L}{ }^{-1}$, unstable angina, left ventricular ejection fraction less than 0.35 , and hepatic failure. Patients were randomized (by a priori random number generation using Graphpad Statmate [San Diego, CA] software) to either the control group or the treatment group.

The groups differed only in their management of shed mediastinal blood. In the control group all cardiotomy suction blood was collected in a cardiotomy suction reservoir and returned to the patient after completion of the last graft. In the treatment group this shed blood was either discarded (if less than $500 \mathrm{~mL}$ total volume) or processed in a Dideco (Mirandola, Italy) compact cell saver and then returned to the patient. This strategy satisfied the requirements of the Research Ethics Committee regarding minimizing the risks of blood transfusion for the patients involved.

\section{Anesthetic Details}

Premedication was standardized to morphine, lorazepam, and hyoscine. Anesthesia was induced using fentanyl to a maximum dose of $25 \mu \mathrm{g} / \mathrm{kg}$ and pancuronium $150 \mu \mathrm{g} / \mathrm{kg}$ to facilitate ventilation. Sedation was provided with target controlled infusion of propofol with a target concentration of 1 to $4 \mu \mathrm{g} \mathrm{mL}^{-1}$. Anesthesia was maintained with increments of fentanyl, propofol infusion, incremental pancuronium, and isoflurane $0 \%$ to $2 \%$ as required. Heparin $1 \mathrm{mg} / \mathrm{kg}$ was administered prior to grafting and the target activated clotting time was 250 seconds. If, at the completion of grafting the activated clotting time exceeded 200 seconds, $1 \mathrm{mg} / \mathrm{kg}$ of protamine sulfate was administered to return this to baseline values.

\section{Surgical Details}

Median sternotomy and the OPCAB stabilizer (Cardiothoracic Systems, Inc, Cupertino, CA) were used in all cases. Occluded or severely stenosed vessels were grafted first and ischemic preconditioning was used on the left anterior descending artery when appropriate. Visualization was enhanced during the procedure by the use of a carbon dioxide and saline blower.

\section{Cell Salvage Details}

A Dideco compact cell saver was utilized for processing salvaged blood when required by the protocol. Collection of blood by cardiotomy suction continued until closure of the sternal wound. This blood was then managed as per randomization in the individual patient, with all retransfusion (washed or unwashed) being complete by the two-hour postgraft completion sample point (plasma time point C). A $225 \mathrm{~mL}$ bowl was used. Centrifuge speed was $5,600 \mathrm{rpm}$. Elimination rate was calculated using the standard formula below:

$$
\begin{aligned}
& \left(\begin{array}{l}
\text { volume of plasma after processing } \\
\times \frac{\times \text { concentration of substance after processing }}{\text { volume of plasma before processing }} \\
\times \text { concentration of substance before processing }
\end{array}\right) \\
& \times 100 .
\end{aligned}
$$

\section{Postoperative Care}

Patients were sedated overnight with propofol and morphine infusions titrated to effect. Extubation was performed the morning after surgery if clinically appropriate. 


\section{Sampling Times and Analysis}

Plasma sampling times were chosen as follows: sample A, before induction of anesthesia; sample $B$, ten minutes after completion of the last graft; samples C, D, E, and F, $2,6,24$, and 48 hours after completion of grafting. In addition, in the treatment group, blood was withdrawn from the shed mediastinal blood before and after it was processed in the cell saver.

Urinary samples were obtained as follows. The bladder was catheterized and emptied (after induction of anesthesia) and $10 \mathrm{~mL}$ obtained as sample A. Thereafter, the first $10 \mathrm{~mL}$ of fresh urine after the bladder had been emptied were obtained (sample B). Sample C was obtained 10 minutes after completion of grafting. Samples D, E, F, G, and $\mathrm{H}$ were obtained at 2, 6, 24, 48, and 72 hours after graft completion, respectively.

Plasma samples were assayed for tumor necrosis factor- $\alpha$ (TNF- $\alpha)$, interleukin-8 (IL-8), and IL-6, as well as the anti-inflammatory cytokines, interleukin-10 (IL-10), interleukin-1 receptor antagonist (IL-1ra), and TNF soluble receptor-2 (TNFsr-2). Samples were also assayed for serum creatinine. Shed mediastinal blood was assayed for TNF- $\alpha$, IL-6, IL-8, TNFSr-2, free hemoglobin, and full blood count. Urinary samples were assayed for IL-1ra, TNFsr-2, creatinine, $\alpha-1$-microglobulin, albumin, and $\beta$-NAG. All cytokine kits were from R+D Systems (Minneapolis, MN) and were sandwich enzyme-linked immunosorbent assay kits.

\section{Statistical Analysis}

Patient demographics and surgical characteristics were analyzed using the Student $t$ test for continuous, normally distributed variables and the $\chi^{2}$ test for categoric variables. Laboratory data were analyzed using two-way repeated measures analysis of variance (ANOVA) with Greenhouse-Geisser correction (the Mauchly test dem-

Table 1. Clinical and Surgical Characteristics

\begin{tabular}{lcc}
\hline Characteristics & Control & Treatment \\
\hline Sex (M:F) & $18: 1$ & $16: 2$ \\
Age (yrs) & $63.3 \pm 8.0$ & $58.6 \pm 8.2$ \\
Height (cm) & $172.9 \pm 9.4$ & $168.9 \pm 7.0$ \\
$\begin{array}{l}\text { Euroscore (additive) } \\
\text { Peripheral vascular disease }\end{array}$ & $1.6 \pm 1.1$ & $1.5 \pm 1.1$ \\
$\quad$ (no. of patients) & 1 & 1 \\
Cerebral vascular disease & 0 & 0 \\
Weight (kg) & $84.2 \pm 10.3$ & $76.0 \pm 11.6^{\mathrm{a}}$ \\
Baseline serum & $83.6 \pm 11.7$ & $75.7 \pm 14.1$ \\
Creatinine ( $\mu$ mol L & & \\
Diseased vessels & & $2.7 \pm 0.6$ \\
Grafts & $2.5 \pm 0.7$ & $2.3 \pm 0.5$ \\
& $($ median $=2)$ & $($ median $=2)$ \\
Occlusion time (min) & $47.4 \pm 11.7$ & $48.3 \pm 15.8$ \\
Shunt used (number) & 1 & 3 \\
\hline
\end{tabular}

a $p<0.05$.

Data presented as mean \pm SD. Analysis with $t$ test or $\chi^{2}$ as appropriate.
Table 2. Postoperative Complications

\begin{tabular}{lcc}
\hline Complication & Control & Treatment \\
\hline Atrial fibrillation & 2 & 1 \\
Transient ischemic attack & 1 & 0 \\
Resternotomy & 1 & 1 \\
Chest infection & 1 & 2 \\
Renal dysfunction & 0 & 2 \\
Compartment syndrome & 0 & 1 \\
Cell saver dysfunction & 0 & 1 \\
Postoperative bleeding & 0 & 1 \\
\hline
\end{tabular}

Number of patients reporting each complication is displayed. One patient can have more than one complication.

onstrated that sphericity assumptions were not met), followed by the Mann-Whitney $U$ test between groups if there was a significant difference detected on ANOVA. In the case of TNF- $\alpha$, as the data were not normally distributed, we also examined area under the curves of concentration against time for each patient. The area under the curve was then compared between groups using the Mann-Whitney $U$ test. The study design assured that one standard deviation real difference would be detected with power greater than $90 \%$.

\section{Results}

\section{Clinical and Demographic Data}

Thirty-seven patients were enrolled in the study. Nineteen patients were randomly allocated to the control group and eighteen to the treatment group. In the washed (treatment) group, fourteen patients had their shed mediastinal blood processed in a cell saver and returned. The remaining four patients in this group had their shed mediastinal blood discarded as per protocol $(<500 \mathrm{~mL}$ total volume). There was no significant difference between groups in the volume of blood collected during surgery $(602 \pm 356 \mathrm{~mL}$ vs $715 \pm 287 \mathrm{~mL})$. The volume retransfused was significantly different between groups as a result of the cell salvage procedure $(565 \pm 330 \mathrm{~mL}$ vs $195 \pm 152 \mathrm{~mL} ; p<0.0001$; Student $t$ test).

Clinical and surgical characteristics are shown in Table 1. Complications occurring in patients are shown in Table 2. There were no deaths in either group and there was no significant difference between the groups in intensive care $(1.5 \pm 1.2$ days vs $1.5 \pm 1.9$ days $)$ or hospital length of stay $(6.1 \pm 1.6$ days vs $7.0 \pm 3.1$ days $)$.

There was a tendency for more blood product usage in the treatment group that achieved significance in the use of platelets ( 0 packs versus 5 packs; $p<0.05 ; \chi^{2}$ test). There was no significant difference in red cell usage $(0.6 \pm 0.9$ packs per patient versus $1.1 \pm 1.7$ packs per patient).

Proinflammatory cytokines were present at increased concentration in cardiotomy suction blood (compared with simultaneous plasma concentrations) while TNFsr-2 
Table 3. Cytokines Before and After Cell Salvage Compared With Simultaneous Plasma Sample

\begin{tabular}{lcccc}
\hline Cytokine & & [2] Unwashed & [3] Postwash & Elimination \\
Rate & Concentration & $47.8 \pm 35.5$ & $96.34 \%$ \\
IL-8 & [1] Plasma Sample B & $124.6 \pm 115.4^{\mathrm{a}}$ & $187.9 \pm 554.6^{\mathrm{c}}$ & $91 . \%^{\circ}$ \\
IL-6 & $45.0 \pm 30.8$ & $585.6 \pm 699.5^{\mathrm{b}}$ & $0.0 \pm 0.0^{\mathrm{d}}$ & $100 \%$ \\
TNF- $\alpha$ & $106.2 \pm 209.4$ & $10.1 \pm 24.2$ & $80.9 \pm 137.8^{\mathrm{f}}$ & $96.95 \%$ \\
TNFsr-2 & $2.6 \pm 4.7$ & $684 \pm 218^{\mathrm{e}}$ & \\
\hline
\end{tabular}

a $p=0.02$, comparing columns [1] and [2]. $\quad{ }^{\mathrm{b}} p=0.001$, comparing column [1] with column [2]. $\quad{ }^{\mathrm{c}} p=0.03$, comparing column [2] with column [3]. $\mathrm{d} p<0.05$, comparing column [2] with column [3]. $\quad \mathrm{e} p=0.0002$, comparing column [1] with column [2]. ${ }^{\mathrm{f}} p=0.0001$ comparing column [2] with column [3].

Table showing [1] plasma sample B (treatment group); taken contemporaneously and from the same patients as [2] shed blood prior to washing; [3] the blood in [2] after washing, just prior to retransfusion.

All values are $\mathrm{pg} \mathrm{mL}^{-1}$, mean $\pm \mathrm{SD}$ and analysis was with Wilcoxon matched pairs signed rank test.

IL-8 = interleukin-8; $\quad$ IL-6 = interleukin-6; $\quad$ TNF- $\alpha=$ tumor necrosis factor- $\alpha ; \quad$ TNFsr-2 = tumor necrosis factor soluble receptor 2 .

was present in lower concentration in shed blood than in the patient's plasma (see Table 3).

The cell salvage was hematologically effective with significant clearance of free hemoglobin from the treated blood (prewash, $382.9 \pm 206.7$; postwash, $242.4 \pm 151.8$, $p<0.05)$. In addition the postsalvage blood had a significantly higher hematocrit $(0.22 \pm 0.07$ vs $0.38 \pm 0.1$, $p<0.005)$.

\section{Cytokine Results}

There was no significant difference between the groups in baseline plasma cytokines: TNF- $\alpha$ : $0.7 \pm 0.6 \mathrm{pg} \mathrm{mL} \mathrm{m}^{-1}$

Table 4. Plasma Cytokine Concentrations

\begin{tabular}{|c|c|c|c|c|}
\hline Cytokine & Time Point & Control & Treatment & $p$ Values ANOVA (2-way) \\
\hline \multirow[t]{5}{*}{ TNF- $\alpha$} & B & $6.9 \pm 15.1$ & $2.2 \pm 4.2$ & Time 0.27 \\
\hline & $\mathrm{C}$ & $6.8 \pm 10.7$ & $3.5 \pm 7.7$ & Group $0.4^{\mathrm{a}}$ \\
\hline & $\mathrm{D}$ & $3.4 \pm 2.7$ & $2.6 \pm 2.3$ & Interactive 0.37 \\
\hline & $\mathrm{E}$ & $2.3 \pm 1.3$ & $1.7 \pm 1.2$ & \\
\hline & $\mathrm{F}$ & $2.3 \pm 1.4$ & $2.2 \pm 1.2$ & \\
\hline \multirow[t]{5}{*}{ IL-8 } & B & $10.8 \pm 14.4$ & $43.6 \pm 117$ & Time 0.07 \\
\hline & $\mathrm{C}$ & $31.7 \pm 38.8$ & $57.4 \pm 126$ & Group 0.3 \\
\hline & $\mathrm{D}$ & $17.8 \pm 7.1$ & $20.7 \pm 15.3$ & Interactive 0.26 \\
\hline & $\mathrm{E}$ & $17.6 \pm 9.8$ & $13.2 \pm 5.9$ & \\
\hline & $\mathrm{F}$ & $10.0 \pm 3.5$ & $10.4 \pm 5.1$ & \\
\hline \multirow[t]{5}{*}{ IL-6 } & B & $73.4 \pm 51.8$ & $94.6 \pm 184.7$ & Time $<0.0001$ \\
\hline & $\mathrm{C}$ & $256 \pm 149$ & $283.8 \pm 199.6$ & Group 0.67 \\
\hline & $\mathrm{D}$ & $395 \pm 199$ & $335.4 \pm 208.5$ & Interactive 0.38 \\
\hline & $\mathrm{E}$ & $342 \pm 192$ & $297.8 \pm 182$ & \\
\hline & $\mathrm{F}$ & $144 \pm 71$ & $125.9 \pm 75.16$ & \\
\hline \multirow[t]{5}{*}{ IL-10 } & B & $19.8 \pm 23.7$ & $18.4 \pm 20.3$ & Time $<0.0001$ \\
\hline & $\mathrm{C}$ & $38.0 \pm 45.7$ & $35.1 \pm 44.3$ & Group 0.39 \\
\hline & $\mathrm{D}$ & $41.1 \pm 38.6$ & $37.4 \pm 41.3$ & Interactive 0.59 \\
\hline & $\mathrm{E}$ & $47.3 \pm 49.1$ & $33.2 \pm 37.8$ & \\
\hline & $\mathrm{F}$ & $19.1 \pm 24.4$ & $11.4 \pm 8.5$ & \\
\hline \multirow[t]{5}{*}{ TNFsr-2 } & B & $1,434 \pm 492$ & $1,190 \pm 460$ & Time $<0.0001$ \\
\hline & $\mathrm{C}$ & $1,974 \pm 595$ & $1,843 \pm 588$ & Group 0.041 \\
\hline & $\mathrm{D}$ & $2,266 \pm 581$ & $2,014 \pm 499$ & Interactive 0.31 \\
\hline & $\mathrm{E}$ & $2,632 \pm 799$ & $2,060 \pm 346$ & \\
\hline & F & $2,150 \pm 741$ & $1,922 \pm 589$ & \\
\hline
\end{tabular}

a TNF- $\alpha$ was significantly lower in the treatment group when analyzed with area under the curve (in view of the non-normal distribution of this data), with between group comparison with the Mann-Whitney $U$ test $(p=0.04)$.

All values in $\mathrm{pg} \mathrm{mL}^{-1}$. Data presented as mean $\pm \mathrm{SD}$.

ANOVA $=$ analysis of variance; $\quad$ IL-8 = interleukin-8; $\quad$ IL-6 = interleukin-6; $\quad$ IL-10 = interleukin-10; $\quad$ TNF- $\alpha=$ tumor necrosis factor- $\alpha$; TNFsr-2 = tumor necrosis factor soluble receptor 2 . 
Table 5. Urinary Laboratory Data

\begin{tabular}{|c|c|c|c|c|}
\hline Marker & Time Point & Control & Treatment & $p$ Values ANOVA \\
\hline \multirow[t]{6}{*}{ TNFsr-2 (pg mL $\left.{ }^{-1}\right)$} & $\mathrm{C}$ & $5,674 \pm 3,182$ & $4,806 \pm 3,208$ & Time $<0.0001$ \\
\hline & $\mathrm{D}$ & $8,383 \pm 4,489$ & $6,254 \pm 2,489$ & Group 0.003 \\
\hline & $\mathrm{E}$ & $15,030 \pm 9,068$ & $7,636 \pm 4,581$ & Interactive 0.14 \\
\hline & $\mathrm{F}$ & $18,190 \pm 12,410$ & $14,090 \pm 9,569$ & \\
\hline & G & $23,450 \pm 10,460$ & $13,800 \pm 13,170$ & \\
\hline & $\mathrm{H}$ & $15,170 \pm 11,030$ & $9,913 \pm 7,888$ & \\
\hline \multirow[t]{6}{*}{ IL-1ra (pg mL $\left.{ }^{-1}\right)$} & $\mathrm{C}$ & $17,760 \pm 20,700$ & $9,597 \pm 6,092$ & Time $<0.0001$ \\
\hline & $\mathrm{D}$ & $35,230 \pm 41,920$ & $15,170 \pm 8,022$ & Group 0.41 \\
\hline & $\mathrm{E}$ & $46,180 \pm 49,740$ & $30,770 \pm 23,430$ & Interactive 0.51 \\
\hline & $\mathrm{F}$ & $23,670 \pm 19,380$ & $25,560 \pm 16,470$ & \\
\hline & G & $20,530 \pm 7,103$ & $15,880 \pm 9,801$ & \\
\hline & $\mathrm{H}$ & $21,890 \pm 23,280$ & $15,470 \pm 18,590$ & \\
\hline \multirow{6}{*}{$\begin{array}{l}\beta \text {-NAG/creatinine ratios } \\
\left(\mu \mathrm{mol} \mathrm{mmol}^{-1} \text { creatinine }\right)\end{array}$} & $\mathrm{C}$ & $152.2 \pm 90.2$ & $153.7 \pm 94.4$ & Time 0.006 \\
\hline & $\mathrm{D}$ & $237.9 \pm 503.8$ & $131.8 \pm 64.1$ & Group 0.37 \\
\hline & $\mathrm{E}$ & $59.4 \pm 50.1$ & $65.5 \pm 37.8$ & Interactive 0.42 \\
\hline & $\mathrm{F}$ & $59.0 \pm 31.0$ & $62.3 \pm 32.2$ & \\
\hline & G & $121.3 \pm 55.7$ & $104.8 \pm 37.7$ & \\
\hline & $\mathrm{H}$ & $84.7 \pm 43.8$ & $76.9 \pm 61.0$ & \\
\hline \multirow{6}{*}{$\begin{array}{l}\text { Alpha }{ }_{1} \text { microglobulin } \\
\text { (mg mmol } \text { creatinine })^{-1}\end{array}$} & $\mathrm{C}$ & $9.9 \pm 4.5$ & $10.8 \pm 5.3$ & Time $<0.0001$ \\
\hline & $\mathrm{D}$ & $13.6 \pm 8.0$ & $12.8 \pm 4.1$ & Group 0.3 \\
\hline & $\mathrm{E}$ & $7.3 \pm 4.4$ & $7.7 \pm 3.0$ & Interactive 0.26 \\
\hline & $\mathrm{F}$ & $8.1 \pm 5.4$ & $8.4 \pm 6.8$ & \\
\hline & G & $8.9 \pm 3.6$ & $8.0 \pm 3.1$ & \\
\hline & $\mathrm{H}$ & $7.1 \pm 3.5$ & $5.8 \pm 3.2$ & \\
\hline
\end{tabular}

Data presented as mean \pm SD.

ANOVA = analysis of variance; $\quad$ IL-1ra = Interleukin-1 receptor antagonist; creatinine ratios $=\mathrm{N}$-acetyl $\beta \mathrm{D}$ glucosaminidase/creatinine ratios.

TNFsr-2 = tumor necrosis factor soluble receptor 2 ; $\quad \beta-N A G /$

vs $1.8 \pm 1.1 \mathrm{pg} \mathrm{mL}^{-1}$; IL-8: $3.3 \pm 1.6 \mathrm{pg} \mathrm{mL}^{-1}$ vs $5.0 \pm$ $7.6 \mathrm{pg} \mathrm{mL}^{-1}$; IL-6: $1.5 \pm 1.0 \mathrm{pg} \mathrm{mL}^{-1}$ vs $2.2 \pm 1.48 \mathrm{pg} \mathrm{mL}^{-1}$; IL-10: $0.8 \pm 2.1 \mathrm{pg} \mathrm{mL}^{-1}$ vs $4.6 \pm 7.9 \mathrm{pg} \mathrm{mL}^{-1}$; TNFsr-2: $1,381 \mathrm{pg} \mathrm{mL}^{-1} \pm 408$ vs $1253 \pm 341 \mathrm{pg} \mathrm{mL}^{-1}$.

Although TNF- $\alpha$ was not significantly different between groups on repeated measures ANOVA, these results demonstrated a markedly skewed distribution. There was one patient in the treatment group who was a clear statistical outlier at time points B and C (both values being three times in excess of the interquartile range). We therefore additionally calculated the mean area under the concentration time curves for plasma TNF- $\alpha$ (excluding this outlier) and this was significantly lower in the treatment group ( $p<0.05$, Mann-Whitney $U$ test).

Plasma IL-8, IL-6, and IL-10 varied with time within groups but demonstrated no significant difference between groups (see Table 4).

Plasma TNFsr-2 rose significantly from baseline, demonstrated significant between group difference on repeated measures ANOVA, and was significantly lower in the treatment group at time point E ( 24 hours after last graft, $p<0.05$ ).

There were no significant differences between baseline (samples A and B) urinary cytokines: urinary TNFsr-2 sample A, 2,446 $\pm 2,374 \mathrm{pg} \mathrm{mL}^{-1}$ vs 1,371 $\pm 1,258$; sample $\mathrm{B}, 2,986 \pm 3,259$ vs $1,730 \pm 1,585$; urinary IL-1ra sample A,
$2,976 \pm 2,423$ vs $2,046 \pm 1,930$; and sample $B, 5,944 \pm 7,178$ vs $5,753 \pm 7,835$.

Urinary TNFsr-2 (Table 5) rose significantly from baseline in both groups and was significantly lower in the treatment group at time point E (six hours after graft completion, $p<0.05$ ) and time point $\mathrm{G}$ (48 hours after graft completion, $p<0.05$ ). There was a significant between group difference on repeated measures ANOVA.

\section{Renal Markers}

There was no significant between group difference in serum creatinine. Urinary $\beta$-NAG/creatinine and $\alpha-1$ microglobulin to creatinine ratios varied significantly with time but there was no between group difference in these variables.

\section{Comment}

We have demonstrated the following three key facts in this study.

- Shed mediastinal blood contains elevated concentrations of cytokines.

- The use of a cell saver effectively removed these cytokines from the washed blood. 
- The management strategy for shed blood in the treatment group produced a net anti-inflammatory change in both plasma and urine.

\section{Shed Mediastinal Blood, Cytokines, and Cell Salvage}

Shed mediastinal blood contains elevated levels of both pro- and anti-inflammatory cytokines. IL- 8 and IL-6 are present in the unwashed blood to significantly higher levels than simultaneous plasma levels. In contrast, TNFsr-2 is present at a significantly lower concentration in shed blood than simultaneously obtained plasma samples. This implies that the balance of pro- and antiinflammatory cytokines within shed mediastinal blood is more proinflammatory than simultaneous plasma samples and raises the possibility of unwelcome proinflammatory effects arising from retransfusion of untreated shed mediastinal blood.

Cell salvage and washing significantly reduced the concentration of all measured cytokines in the processed blood with elimination rates in excess of $90 \%$. In particular, the concentration of TNF- $\alpha$ was below the lower limit of detection for the assay $\left(<4.4 \mathrm{pg} \mathrm{mL}^{-1}\right)$ after cell salvage and washing. In contrast, TNFsr-2 in the processed blood was reduced but not removed. This suggests that the cell salvage and washing process has pushed pro- and antiinflammatory cytokine balance, within the treated blood, in an anti-inflammatory direction, which is a progression on other reports of washing leading to reduced proinflammatory mediators only $[29,33]$.

The efficiency of the cell salvage and washing process is indicated by the removal of free hemoglobin from the processed blood. The elimination rate for free plasma hemoglobin was $84 \%$, in keeping with data reported by a number of authors, demonstrating that the washing process was functioning correctly and efficiently [33].

It was noted that there was an increased requirement for platelet transfusion (but not for packed red cells or other blood products) in the treatment group. Because this study was neither designed nor powered to examine clinical endpoints, such as bleeding complications or transfusion requirements, the possibility of a type I error cannot be excluded without further study.

\section{Management of Shed Blood and the Inflammatory Response}

We have demonstrated that avoiding the retransfusion of unwashed shed mediastinal blood beneficially alters the plasma and urinary cytokine response to OPCAB, unlike others who at cardiopulmonary bypass failed to show such an effect $[27,28,35]$. The likely explanation for these results is that washing-discarding shed blood reduced either the direct proinflammatory cytokine load returned to the patient or the return of other inflammatory mediators and cells capable of generating an enhanced proinflammatory cytokine response. This resulted in reduced plasma TNF- $\alpha$ (albeit of borderline statistical significance) in the treatment group, which led to reduced plasma TNFsr-2 (which, being a compensatory and amplifying response to TNF- $\alpha$, reflects earlier alterations in TNF- $\alpha$ concentrations) [36-38]. We know that unwashed shed blood contained increased TNF- $\alpha$ before retransfusion resulting in a heightened TNF- $\alpha$ plasma load. The fact that this led to only a marginally detectable plasma TNF- $\alpha$ rise possibly reflects the dilutional effect of distribution throughout the circulation and efficient renal clearance. Nevertheless, the biological significance of introducing this additional TNF- $\alpha$ to the circulation is seen in the amplified, compensatory increases in urinary and plasma anti-inflammatory TNFsr-2. This demonstration of significant between group difference with plasma and urinary TNFsr-2 highlights the usefulness of urinary and plasma TNFsr-2 changes in detecting and amplifying biologically significant changes in TNF- $\alpha$, which are not necessarily detectable by TNF- $\alpha$ plasma sampling in patients with normal renal function. This is due to the signal amplification that results from binding of one TNF- $\alpha$ molecule with subsequent shedding of many TNF soluble receptors [36].

The reduction in urinary TNFsr-2 in the treatment group is likewise consistent with a reduced plasma proinflammatory load in these patients. As noted before, the concentration of TNFsr-2 in urine was far in excess of that in plasma and is thought to reflect an intrarenal source for this anti-inflammatory cytokine which provides an intrarenal compensatory and protective response during renal filtration and removal of plasma proinflammatory TNF- $\alpha[3,10]$. Consistent with this reasoning $[3,10]$ is the suggestion that a reduction in plasma TNF- $\alpha$ concentrations in the treatment group results in reduced filtered TNF- $\alpha$ appearing in the proximal tubule leading to a less intense tubular antiinflammatory compensatory response resulting in lower concentration of urinary TNFsr-2 in the treatment group. The alteration of both plasma and urinary antiinflammatory cytokines in the treatment group strongly confirms our interpretation that a reduced plasma TNF- $\alpha$ reflects an overall reduced proinflammatory insult in this group. The failure of earlier reports [27, 28, 39] to demonstrate an associated effect on the systemic cytokine response after retransfusion may reflect the fact that all of these studies were performed during surgery with $\mathrm{CPB}$ and it is possible that the small, but significant, effect of cell salvage was obscured in the overall CPB inflammatory response.

\section{Shed Mediastinal Blood and Renal Markers}

The significant reduction of the inflammatory response accompanying washing retransfused mediastinal shed blood has confirmed that this technique can form part of an overall perioperative inflammatory limitation strategy. However, the absence of a between group difference in renal markers shows that such a technique is more likely to be clinically successful when it forms part of an overall perioperative inflammatory limitation strategy combining many strands. Furthermore the renal injury observed in both groups (which existed prior to retransfusion of shed blood) probably reflects the significant and equal inflammatory response seen in both groups prior to our intervention, thus reinforcing the importance of a multifaceted approach that involves interventions having an effect from the outset. The retransfusion of washed 
shed blood helps minimize the postrevascularization inflammatory insult. However, the biological effects of this may be less pronounced if unaccompanied by prerevascularization anti-inflammatory measures. In addition, the lack of statistically significant differences in renal function in this study may also reflect the low renal risk of the patients studied and a further study in a higher risk group of patients with less renal functional reserve is needed. Because the unwashed group contained a relatively broad range of transfusate volume (220 to 1,305 $\mathrm{mL}$ ), with some patients receiving small volumes and others receiving much larger, this means that the range of severity of potential insult arising from unwashed transfusate was wide.

If we had restricted inclusion in the unwashed group to only those patients who had $500 \mathrm{~mL}$ or greater of shed blood, then perhaps a uniformly significant injurious renal insult would have translated into clinically significant detectable outcomes. Further study is required to investigate this.

We have demonstrated that the management of shed mediastinal blood alters the perioperative inflammatory response to $\mathrm{OPCAB}$ surgery as measured by systemic urinary and plasma cytokine changes. Although we did not demonstrate significant changes in renal subclinical markers in this low renal risk group of patients, we demonstrated reductions in urinary antiinflammatory cytokines, suggesting that the upstream reduction in plasma TNF- $\alpha$ load was biologically significant. Because the subclinical outcomes measured were already deranged prior to the study intervention, as a result of surgery alone, avoidance of a biologically significant insult such as retransfusion of cardiotomy suction blood did not measurably obviate an already well-established response in these low risk patients. The systemic inflammatory response has many contributing factors and we have confirmed that retransfusion of cardiotomy suction blood should not be overlooked in this context. Accordingly, washing of cardiotomy suction blood prior to retransfusion may be considered as part of a comprehensive perioperative inflammatory limitation strategy. However, studies of higher risk patients are required to determine the degree of clinical protection such a potentially expensive intervention will confer. Finally, this study confirms the importance of shed mediastinal blood as a confounding variable in studies that examine the inflammatory cytokine response at cardiac surgery.

This work is attributed to the Departments of Anaesthesia, Immunobiology and Clinical Chemistry, Queens University, Belfast. Dr Allen was supported by a Research Fellowship provided by the Royal Victoria Hospital, Belfast. Additional funding was obtained from the Heart Fund Trust, Northern Ireland. We thank Elizabeth Fleming and Elizabeth McClean for assistance with the various assays performed. In addition we acknowledge the assistance of the perfusion staff in this work.

\section{References}

1. Gormley SM, Armstrong MA, McMurray TJ, McBride WT. The effect of methylprednisolone on cytokine concentration and leukocyte adhesion molecule expression in an isolated cardiopulmonary bypass system. Cytokine 2003;22:149-55.

2. Bedi A, McBride WT, Armstrong MA, Murray JM, Fee JP. Xenon has no effect on cytokine balance and adhesion molecule expression within an isolated cardiopulmonary bypass system. Br J Anaesth 2002;894:546-50.

3. Gormley SM, McBride WT, Armstrong MA, et al. Plasma and urinary cytokine homeostasis and renal function during cardiac surgery without cardiopulmonary bypass. Cytokine 2002;17:61-5.

4. McBride WT, Armstrong MA, Crockard AD, McMurray TJ, Rea JM. Cytokine balance and immunosuppressive changes at cardiac surgery: contrasting response between patients and isolated CPB circuits. Br J Anaesth 1995;75:724-33.

5. Wan S, LeClerc JL, Vincent JL. Inflammatory response to cardiopulmonary bypass: mechanisms involved and possible therapeutic strategies. Chest 1997;112:676-92.

6. McBride WT, Armstrong MA, McBride SJ. Immunomodulation: an important concept in modern anaesthesia. Anaesthesia 1996;51:465-73.

7. Laffey JG, Boylan JF, Cheng DC. The systemic inflammatory response to cardiac surgery: implications for the anesthesiologist. Anesthesiology 2002;97:215-52.

8. McBride WT, Armstrong MA, Gilliland H, McMurray TJ. The balance of pro and anti-inflammatory cytokines in plasma and bronchoalveolar lavage (BAL) at paediatric cardiac surgery. Cytokine 1996;8:724-9.

9. McBride WT, Allen S, Gormley SM, et al. Methylprednisolone favourably alters plasma and urinary cytokine homeostasis and sub-clinical renal injury at cardiac surgery. Cytokine 2005;27:81-9.

10. Gormley SM, McBride WT, Armstrong MA, et al. Plasma and urinary cytokine homeostasis and renal dysfunction during cardiac surgery. Anesthesiology 2000;93:1210-6.

11. Baker RC, Armstrong MA, Allen SJ, McBride WT. Role of the kidney in perioperative inflammatory responses. Br J Anaesth 2002;88:330-4.

12. Westhuyzen J, McGiffin DC, McCarthy J, Fleming SJ. Tubular nephrotoxicity after cardiac surgery utilising cardiopulmonary bypass. Clin Chim Acta 1994;228:123-32.

13. Westhuyzen J, Endre ZH, Reece G, Reith DM, Saltissi D, Morgan TJ. Measurement of tubular enzymuria facilitates early detection of acute renal impairment in the intensive care unit. Nephrol Dial Transplant 2003;18:543-51.

14. Price RG. Measurement of N-acetyl-beta-glucosaminidase and its isoenzymes in urine methods and clinical applications. Eur J Clin Chem Clin Biochem 1992;30:693-705.

15. Boldt J, Brenner $T$, Lang J, Kumle B, Isgro F. Kidney-specific proteins in elderly patients undergoing cardiac surgery with cardiopulmonary bypass. Anesth Analg 2003;97:1582-9.

16. Gu YJ, Mariani MA, van Oeveren W, Grandjean JG, Boonstra PW. Reduction of the inflammatory response in patients undergoing minimally invasive coronary artery bypass grafting. Ann Thorac Surg 1998;65:420-4.

17. Matata BM, Sosnowski AW, Galinanes M. Off-pump bypass graft operation significantly reduces oxidative stress and inflammation. Ann Thorac Surg 2000;69:785-91.

18. Fransen E, Maessen J, Dentener M, Senden N, Geskes G, Buurman W. Systemic inflammation present in patients undergoing $\mathrm{CABG}$ without extracorporeal circulation. Chest 1998;113:1290-5.

19. Ascione R, Lloyd CT, Underwood MJ, Lotto AA, Pitsis AA, Angelini GD. Inflammatory response after coronary revascularization with or without cardiopulmonary bypass. Ann Thorac Surg 2000;69:1198-1204.

20. Struber M, Cremer JT, Gohrbandt B, et al. Human cytokine responses to coronary artery bypass grafting with and without cardiopulmonary bypass. Ann Thorac Surg 1999;68: $1330-5$. 
21. Czerny M, Baumer H, Kilo J, et al. Inflammatory response and myocardial injury following coronary artery bypass grafting with or without cardiopulmonary bypass. Eur J Cardiothorac Surg 2000;17:737-42.

22. Ascione R, Lloyd CT, Underwood MJ, Gomes WJ, Angelini GD. On-pump versus off-pump coronary revascularization: evaluation of renal function. Ann Thorac Surg 1999;68:493-8.

23. Cleveland JC Jr, Shroyer AL, Chen AY, Peterson E, Grover FL. Off-pump coronary artery bypass grafting decreases risk-adjusted mortality and morbidity. Ann Thorac Surg 2001;72:1282-8.

24. Mack MJ, Pfister A, Bachand D, et al. Comparison of coronary bypass surgery with and without cardiopulmonary bypass in patients with multivessel disease. J Thorac Cardiovasc Surg 2004;127:167-73.

25. Hayashida N, Teshima H, Chihara S, et al. Does off-pump coronary artery bypass grafting really preserve renal function? Circ J 2002;66:921-5.

26. Tang AT, Knott J, Nanson J, Hsu J, Haw MP, Ohri SK. A prospective randomized study to evaluate the renoprotective action of beating heart coronary surgery in low risk patients. Eur J Cardiothorac Surg 2002;22:118-23.

27. Schmidt H, Bendtzen K, Mortensen PE. The inflammatory cytokine response after autotransfusion of shed mediastinal blood. Acta Anaesthesiol Scand 1998;42:558-64.

28. Svenmarker S, Engstrom KG. The inflammatory response to recycled pericardial suction blood and the influence of cell-saving. Scand Cardiovasc J 2003;37:158-64.

29. Reents W, Babin-Ebell J, Misoph MR, Schwarzkopf A, Elert O. Influence of different autotransfusion devices on the quality of salvaged blood. Ann Thorac Surg 1999;68:58-62.

30. Bengtsson A, Avall A, Hyllner M, Bengtson JP. Formation of complement split products and proinflammatory cytokines by reinfusion of shed autologous blood. Toxicol Lett 1998; 100-101:129-33.

31. Avall A, Hyllner M, Bengtson JP, Carlsson L, Bengtsson A. Greater increase in cytokine concentration after salvage with filtered whole blood than with washed red cells, but no difference in postoperative hemoglobin recovery. Transfusion 1999;39:271-6.

32. Tylman M, Bengtson JP, Avall A, Hyllner M, Bengtsson A Release of interleukin-10 by reinfusion of salvaged blood after knee arthroplasty. Intensive Care Med 2001;27:1379-84.

33. Amand T, Pincemail J, Blaffart F, Larbuisson R, Limet R, Defraigne JO. Levels of inflammatory markers in the blood processed by autotransfusion devices during cardiac surgery associated with cardiopulmonary bypass circuit. Perfusion 2002;17:117-23.

34. Westerberg M, Bengtsson A, Jeppsson A. Coronary surgery without cardiotomy suction and autotransfusion reduces the postoperative systemic inflammatory response. Ann Thorac Surg 2005;78:54-9.

35. Aldea GS, Soltow LO, Chandler WL, et al. Limitation of thrombin generation, platelet activation, and inflammation by elimination of cardiotomy suction in patients undergoing coronary artery bypass grafting treated with heparin-bonded circuits. J Thorac Cardiovasc Surg 2002; 123:742-55.

36. Van Zee KJ, Kohno T, Fischer E, Rock CS, Moldawer LL, Lowry SF. Tumor necrosis factor soluble receptors circulate during experimental and clinical inflammation and can protect against excessive tumor necrosis factor alpha in vitro and in vivo. Proc Natl Acad Sci U S A 1992;89:4845-9.

37. Aderka D. The potential biological and clinical significance of the soluble tumor necrosis factor receptors. Cytokine Growth Factor Rev 1996;7:231-40.

38. Wei M, Kuukasjarvi P, Laurikka J, et al. Inflammatory cytokines and soluble receptors after coronary artery bypass grafting. Cytokine 2001;15:223-8.

39. Walpoth BH, Eggensperger N, Hauser SP, et al. Effects of unprocessed and processed cardiopulmonary bypass blood retransfused into patients after cardiac surgery. Int J Artif Organs 1999;22:210-6. 